\section{Prof. P. H. Stroobant}

WE record with regret the death at the age of sixty-eight years, after a painful illness, of Prof. Paul Henri Stroobant, honorary director of the Royal Observatory of Belgium at Uecle. Prof. Stroobant had only recently retired from the directorship of the Observatory which, in May 1935, had celebrated the hundredth anniversary of its foundation. On the occasion of the centenary celebrations, which were honoured by the presence of King Leopold and attended by many foreign delegates, the new equipment of the Observatory was open to inspection. This equipment includes an elaborate Ascania meridian circle of $19 \mathrm{~cm}$. aperture; a Cooke-Zeiss equatorial of $45 \mathrm{~cm}$. aperture and $7 \mathrm{~m}$. focal length, with micrometer; a double Zeiss astrograph, each telescope having quadruplet lenses of $40 \mathrm{~cm}$. aperture and $2 \mathrm{~m}$. focal length, covering a field of 72 square degrees; a Zeiss astrographic triplet of $30 \mathrm{~cm}$. aperture and $1.5 \mathrm{~m}$. focal length, covering a field of 81 square degrees; a $7^{\circ}$ objective prism; a Zeiss reflector of $100 \mathrm{~cm}$. aperture, equipped with two spectrographs ; and also comparators and measuring machines. The modernization and reorganization of the Observatory was Prof. Stroobant's chief work as director, to which post he was appointed on May 1, 1925. He had previously been, since 1904, professor of astronomy in the University of Brussels.

Prof. Stroobant's astronomical work included the study of the personal equation in the observation of star transits ; dynamical investigations on the planets and their satellites and, in particular, on the system of Saturn ; researches on the distribution and number of the asteroids; investigations of the motions of the helium stars and of the solar motion. He was the first to establish that the apex of the solar motion and the velocity of the sun, with respect to the near stars, varies in a systematic manner with the spectral type of the stars. A volume entitled "Les Observatoires Astronomiques et les Astronomes", compiled in 1907 by Prof. Stroobant with the assistance of some of the staff of the Uccle Observatory, is a valuable reference work. A revised edition was published in 1931 under the auspices of the International Astronomical Union.

Prof. Stroobant was a correspondant of the Paris Academy of Sciences, of the Bureau des Longitudes, and of the Institut de Coimbra. He was an associate of the Royal Astronomical Society, president of the Belgian National Committee of Astronomy and president of the Commission on Bibliography of the International Astronomical Union.

\section{Dr. Edward Weston}

Bx the death of Dr. Edward Weston on August 20, the electrical industry loses one of its greatest pioneers. Born in 1850, on the border line between England and Wales, he went to the United States when fifteen years old and devoted his energies to studying the action of existing direct current dynamos and making improvements on them. If not the first, he was one of the first to realize the necessity of laminating the iron in the armature of a dynamo so as to obviate the heavy losses that otherwise occurred owing to the eddy currents induced by the alternating magnetic flux. Edison also worked on this problem, and the efficiency of the dynamo was soon raised from 50 to 90 per cent.

As a working method for the realization of the international volt, the Weston cadmium cell is used. At $20^{\circ} \mathrm{C}$. its electromotive force is 1.0183 international volts. The researches made by Sir Frank Smith on this cell, and the modifications in the materials used to which these researches led, have made the Weston cell most trustworthy for the accurate measurement of voltages.

To electrical engineers, Dr. Weston's name is a household word in connexion with moving coil ammeters, voltmeters and wattmeters. The law governing a coil moving in a permanent magnetic field was used by Kelvin on his siphon recorders and by D'Arsonval in his galvanometer. In 1888, Weston, using this principle, developed and produced the first moving coil ammeters and voltmeters. Devices are now used by makers in all parts of the world for measuring amperes, volts and watts which use the essential principles of the original Weston instruments. In the original Weston p.c. ammeter, the coil is pivoted and is controlled by spiral springs which carry the current, but unlike the D'Arsonval galvanometer a pointer is substituted for the mirror. The ammeter can be converted into a voltmeter by using it in conjunction with a high resistance and into an ammeter for measuring large currents by shunting it with a low resistance.

Dr. Weston was the first to employ bakelite, so widely used to-day, on a commercial scale. Amongst his many inventions are a compensated thermocouple instrument for high-frequency A.c. measurements, the rectifier bridge for A.C. measurements and the first commercially practical dry disk photoelectric cell.

Dr. Weston was a past president of the American Institute of Electrical Engineers, and received many honours from learned societies. In 1933 he was awarded the Lamme medal of the Institute for his achievements in the development of electrical apparatus, "especially in connexion with precision measuring instruments". At the time of his death he was a director of the Weston Electric Instrument Corporation and the Weston Electrical Instrument Co. Ltd., at Surbiton. $\mathrm{He}$ is survived by his son, Mr. E. F. Weston, the president of the American company.

A. R.

\section{WE regret to announce the following deaths :}

Dr. W. H. Harrison, formerly Imperial agricultural research chemist for the Government of India, lately acting agricultural adviser, on August 18, aged fiftynine years.

Prof. K. K. Mathur, honorary professor of geology in the Benares Hindu University, and principal of the College of Science, Benares, on July 18. 